\title{
DNA Phase Behavior in the Presence of Oppositely Charged Surfactants
}

\author{
Rita Dias, ${ }^{\dagger, \ddagger}$ Sergey Mel'nikov, ${ }^{\ddagger, \S}$ Björn Lindman, ${ }^{\dagger, \ddagger}$ and Maria G. Miguel*,† \\ Departamento de Química, Universidade de Coi mbra, 3004-535 Coi mbra, Portugal; \\ Physical Chemistry 1, Center for Chemistry and Chemical Engineering, P.O. Box 124, \\ 22100 Lund, Sweden; and Unilever Research Laboratorium, Olivier van Noortlaan 120, \\ P.O. Box 114, 3130 AC Vlaardingen, The Netherlands
}

Received May 3, 2000. In Final Form: J uly 10, 2000

\begin{abstract}
The interaction between DNA and alkyltrimethylammonium bromides of various chain lengths has been investigated. It is known that these systems phase separate with the formation of a preci pitate; this important featureallows, for example, purification of nucleicacids. Phasemaps weredrawn for theaqueous systems illustrating the associative phase separation. The boundary of the two-phase region for the dilute part of the phase diagram was evaluated by turbidimetry, in both the absence and presence of salt. The extension of the precipitate region increases strongly with the surfactant alkyl chain length, and we observed no redissolution with an excess of surfactant. The addition of $\mathrm{NaBr}$ led to novel interesting findings. The phase diagram studies were correlated with the single molecule conformational behavior of the same systems as studied for very di luted sol utions by fluorescencemi croscopy. DNA exhibits a discrete phase transition in the presence of cationic surfactants from coils to gl obules. Results demonstrate that the coil-globule coexistence interval is narrow for CTAB and becomes wider for the shorter-chained surfactant. The findings for flexible polyions of lower charge density differ qualitatively from what we find here for DNA. F or the first, large amounts of surfactant have to be added before phase separation occurs, and the changein the polyion extension is gradual, indicating an essentially uniform distribution of surfactant aggregates among the different polyions. For DNA, the very low values of surfactant concentration at which phase separation starts demonstrate a different binding interaction; as binding to a polyion starts, further binding is facilitated, and one DNA molecule is saturated before binding starts at another.
\end{abstract}

\section{Introduction}

Mixtures of water-soluble polymers and surfactants are present in a large number of systems in nature and industrial applications, as in foods, pharmaceutical formulations, cosmetics, detergents, paints, etc., and these systems are the subject of a large number of studies. ${ }^{1,2}$ The interactions between amphiphilic molecules and biologically active polyel ectrolytes not only have received particular attention from the physical chemistry viewpoint but al so werespecial ly investigated in biomedical studies. Within this group, the DNA - cationic surfactant systems have a number of applications: DNA can be purified by condensation and precipitation by using cationic surfactants; ${ }^{3}$ cetyltrimethylammonium bromide has been used for DNA renaturation and ligation. ${ }^{4}$ There are also applications in controlled delivery of genetic material. Novel vehicles have been tested for the delivery of DNA into cells. Naked DNA, due to its size and charge density, is unlikely to enter in thecells by itself. In this connection, liposomes have been recently used as vehicles for gene delivery. ${ }^{5}$ Synthetic surfactants cannot be used for this

\footnotetext{
† Universidade de Coimbra.

₹ Center for Chemistry and Chemical Engineering.

$\S$ Unilever Research Laboratorium.

* Corresponding author. E-mail: mgmiquel @ci.uc.pt.
}

(1) Goddard, E.; Ananthapadmanabhan, K. Interactions of Surfactants with Polymers and Proteins; CRC Press: Boca Raton, FL, 1993

(2) J önsson, B.; Lindman, B.; Hol mberg, K.; Kronberg, B. Surfactants and Polymers in Aqueous Solution; J ohn Wiley \& Sons: New York, 1998.

(3) Trewavas, A. Anal. Biochem. 1967, 21, 324-329.

(4) Pontius, B.; Berg, P. Proc. Natl. Acad. Sci. U.S.A. 1991, 88, 82378241.

(5) Lasic, D. Liposomes in Gene Delivery; CRC Press: Boca Raton, $\mathrm{FL}, 1997$. purpose, sincethecomplexes of DNA and cationic micelles do not result in effective transfection. It is a common viewpoint to explain this low transfection by the cytotoxicity of surfactants and low stability of thesecomplexes upon a change in the environment. ${ }^{5}$ Despite this, quaternary ammonium detergents can be used, in small amounts, for positive charging of neutral liposomes, improving their transfection efficiency. ${ }^{5}$

Because of the growing interest in this field and numerous applications of these systems, several studies have been presented. It was demonstrated through the use of cationicsurfactant-sel ective el ectrodes that cationic surfactants bind to the negatively charged DNA macromolecule in a cooperative manner. ${ }^{6-9}$ Many techniques have been used to study the complex formation of DNA with quaternary ammoni um surfactants ${ }^{10,11}$ as well as its structure, 8,12,13 giving rise to the model of the formation of micelle-like aggregates on the DNA surface. Fluorescence microscopy has also been used for the observation of single DNA molecules in solution and the effects of

(6) Hayakawa, K.; Santerre, J .; Kwak, J . J . Biophys. Chem. 1983, 17, 175-181.

(7) Shirahama, K.; Takashima, K.; Takisawa, N. Bull. Chem. Soc. pn. 1987, 60, 43-47.

(8) Gorelov, A.; Kudryashov, E.; J acquier, J .-C.; McLoughlin, D.; Dawson, K. Physica A 1998, 249, 216-225.

(9) Mel'nikov, S. M.: Sergeyev, V. G.: Yoshikawa, K. In Recent Research Developments in Chemical Sciences; Pandalai, S. G., Ed.; Transworld Research Network: Trivandrum, India, 1997; Vol. 1, pp 69-113.

(10) Ghirlando, R.; Wachtel, E.; Arad, T.; Minsky, A. Biochemistry 1992, 31, 7110-7119.

(11) Spink, C.; Chaires, J. J . Am. Chem. Soc. 1997, 119, 1092010928.

(12) J acquier, J .-C.; Gorelov, A.; McLoughlin, D.; Dawson, K. J Chromatogr. A 1998, 817, 263-271.

(13) Buckin, V.; Kudryashov, E.; Morrissey, S.; Kapustina, Y.; Dawson, K. Prog. Colloid Polym. Sci. 1998, 110, 214-219. 
cationicsurfactants on its conformational behavior. ${ }^{9,14}$ This technique allows for the observation of the discrete character of thecoil-globuletransition in individual DNA molecules, avoiding the effect of the interaction between the polymer chains.

Although it is well-known that precipitation of DNA occurs in the presence of cationic surfactants, 15 the phase behavior of DNA in the presence of oppositely charged surfactants has never been presented in theliterature. In an attempt to fill this gap, a study was conducted for the aqueous systems of DNA and the cationic surfactants, cetyltrimethylammonium bromide (CTAB), tetradecyltrimethylammonium bromide (TTAB), and dodecyltrimethylammonium bromide (DTAB).

Surfactant molecules, due to their amphi philic nature, have the ability to form self-assemblies in solution. The presence of other compounds, like polymers, may substantially influencethis process. Phasediagrams describe the region of existence of different phases and the equilibrium between them. In these maps one can read out how many phases are formed and what are the compositions of individual phases and their main characteristics. For a three-component system it is common to consider a ternary phase diagram, but for the present case it is more correct to consider it as a pseudoternary one. Since water and two salts with no common ions are present, wehave a four-component system that should be represented by pyramid-shape phase diagrams ${ }^{16}$ or trigonal bipyramids. ${ }^{17}$ Obviously, this three-dimensional representation contains more information than the ternary phase diagrams, but for simplification the former one is preferred, and it consists of a particular cut through the pyramidal body. ${ }^{18}$

Considering a pseudoternary mixture of polymer, surfactant, and water, the simpl est type of phase separation in such systems involves the formation of two phases. If there are strong attractive interactions between the two components, we will be facing the formation of one phase concentrated in both polymer and surfactant and theother diluted in both components, i.e., an associative phase separation. If, on the contrary, there are no attractive interactions between the polymer and surfactant, there will be segregation into two phases: one enriched in polymer and another in surfactant. A schematic representation of the two situations is represented in Figure 1. Since our systems are of the type of polyelectrolyte and oppositely charged surfactant, a strong association between the components with a phase separation is expected.

The boundary of the two-phase region for the diluted region of the phase diagram was evaluated for the three systems by turbidimetry. The effect of theaddition of salt was also investigated.

In this work we also study the three systems by fluorescence microscopy in order to evaluate the differences produced on the DNA conformational behavior by changing the surfactant alkyl chain length.

\section{Experimental Part}

Materials. Synthetic surfactants, cetyltrimethylammonium bromide (CTAB), tetradecyltrimethylammonium bromide (TTAB), and dodecyltrimethylammonium bromide(DTAB), wereobtained

(14) Mel'nikov, S.; Sergeyev, V.; Yoshikawa, K. J . Am. Chem. Soc. 1995, 117, 2401-2408.

(15) Dutta, S.; J ones, A.; Stacey, M. Biochim. Biophys. Acta 1953 $10,613-622$.

(16) Thal berg, K.; Lindman, B.; Karlström, G. J . Phys. Chem. 1991 95, 6004-6011.

(17) J okela, P.; J önsson, B.; Wennerström, H. Prog. Colloid Polym. Sci. 1985, 70, 17-22.

(18) Marques, E.; Khan, A.; Miguel, M.; Lindman, B.J . Phys. Chem. 1993, 97, 4729-4736.
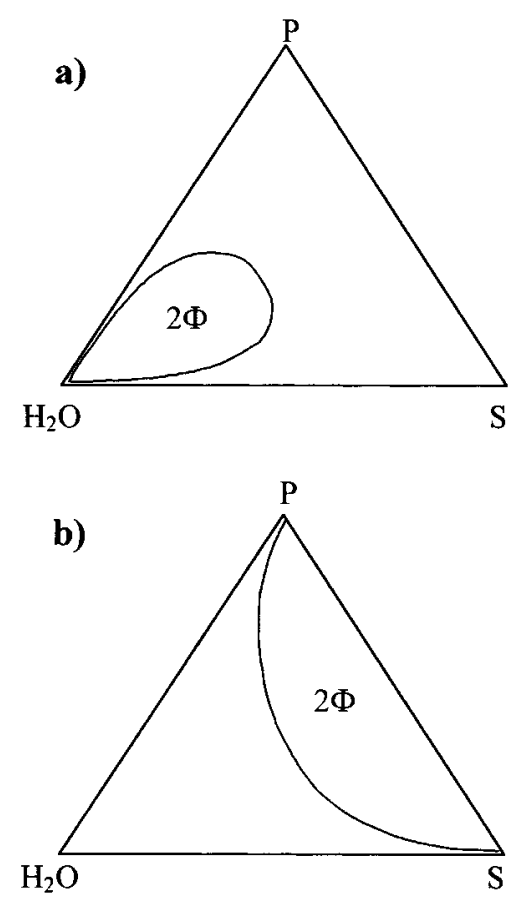

Figure 1. Schematic ternary phase diagram showing (a) associative and (b) segregative phase separation in mixed solutions of polymer and surfactant.

from Sigma, and sodium octyl sulfate (SOS) was from Merck. CTAB was recrystallized twice with acetone. TTAB, DTAB, and SOS were used as received. For phase diagram determinations DNA type XIV from herring testes was purchased from Sigma without further indication. Its mol ecular weight was determined by gel electrophoresis and found to have a polydisperse value between 400 and 1000 base pairs, bp, with a center of distribution at ca. $700 \mathrm{bp}$. For fluorescence microscopy studies coliphage T4 DNA (M $=1.1 \times 10^{8} \mathrm{Da}$, ca. $167 \mathrm{kbp}$ ) was supplied by Sigma. TheDNA concentrations were determined spectrophotometrically considering the molar extinction coefficient of DNA bases to be equal to $6600 \mathrm{M}^{-1} \mathrm{~cm}^{-1} .{ }^{19}$ The ratios of the stock solutions were found to be 1.8 and 1.9 for thetwotypes of DNA. Thefluorescence dye, 4',6-diamidino-2-phenylindole (DAPI), the antioxidant, 2-mercaptoethanol (ME), and the buffer, Tris- $\mathrm{Cl}$, were from Sigma. $\mathrm{NaBr}$, analytical grade, was purchased from Mallinckrodt, Inc.

Sample Preparation. F or the phasediagram determi nation several samples were prepared by weight, adding the desired amount of surfactant and DNA stock solutions, and water, with a total of 1 or $2 \mathrm{~mL}$, in glass ampules that wereflame-sealed. The samples were mixed for at least $48 \mathrm{~h}$ and left for several days to equilibrate at $25^{\circ} \mathrm{C}$, being regularly examined visually and between crossed polaroids. Afterward, the samples were centrifuged at 3500 rpm for $90 \mathrm{~min}$ and again left to equilibrate. In the di luteregion, and to detect thefirst appearance of preci pitate, samples were prepared by volume in screw-capped glass tubes with a total of $1 \mathrm{~mL}$. They were placed in a shaker for $4 \mathrm{~h}$ and left to equilibrate for at least $48 \mathrm{~h}$. The turbidity of the samples was measured on a Perkin-E Imer UV/vis L ambda 14 spectrometer two times at two different wavelengths, 350 and $400 \mathrm{~nm}$. To analyze the precipitate, samples were prepared by weight, keeping the amount of DNA constant and changing the [DTAB]/ [DNA] mixing ratio. The samples were thoroughly mixed for 48 $\mathrm{h}$ and kept for equilibration during $72 \mathrm{~h}$. All the samples were prepared in previously weighted corked tubes. For fluorescence microscopy studies DNA molecules were diluted with $10 \mathrm{mM}$ Tris- $\mathrm{Cl}$ buffer ( $\mathrm{pH}=7.6)$, the antioxidant, the fluorescent dye, and bidistilled water. The final concentration was DNA in nucleotide units $0.5 \mu \mathrm{M}$, DAPI $0.5 \mu \mathrm{M}$, and ME $4 \%(\mathrm{v} / \mathrm{v})$. Under these conditions, the binding number of DAPI per 1 bp DNA is,

(19) Sambrook, J .; Fritsch, E. F.; Maniatis, T. Molecular Cloning: a Laboratory Manual; Cold Spring Harbor Laboratory Press: New Y ork, 1989. 
in an aqueous buffer solution, estimated to be equal to 0.05 , and the persistence length of the DNA chain is expected to remain nearly the same as in the absence of DAPI. ${ }^{20,21}$ The surfactant was added stepwise, and the solution was gently mixed and left at least $30 \mathrm{~min}$ to equilibrate before observation.

Phase Diagram Determination. This determination involved the preparation of over 100 samples for each of the three surfactants, and its observation for approximately 6 months. Thetwo-phase boundary in the diluteregion was determined by turbidimetry. All samples were kept at $25^{\circ} \mathrm{C}$.

Analysis of the Precipitate. To analyze the precipitate of samples, the following procedure, described elsewhere, ${ }^{22}$ was followed. After equilibration the supernatant was separated from the precipitate, and this was lyophilized. The weight percent of theobtained precipitatewas plotted against the DTAB and DNA charge concentration mixing ratio, [DTAB]/[DNA], at constant DNA amount. It is impossible to remove the totality of the supernatant from thesample. Whilefor a low DTAB concentration this will have a negligible effect, for the high concentrated DTAB samples this contribution cannot be ignored. F or this reason a study of the amount of water in the supernatant was also conducted. For this analysis a suitableamount of thesupernatant was carefully pipetted into a preweighted tube that was freeze dried for $72 \mathrm{~h}$, in the same way as the wet precipitate. The dependence of amount of free water in the supernatant on the increase of DTAB concentration at constant DNA concentration was also plotted.

Fluorescence Microscopy. For fluorescence microscopy studies thesamples wereilluminated with a $365 \mathrm{nmUV}$-mercury lamp, and the fluorescenceimages of singleDNA mol ecules were observed using a Zeiss Axioplane mi croscope, equipped with a $100 \times$ oil-immersed objective lens, and digitized on a personal computer through a highly sensitive SIT C-video camera and an image processor, Argus-20 (Hamamatsu Photonic, J apan). The apparent long-axis length of the DNA molecules, $L$, was defined as the longest distance in the outline of the fluorescence images of singleDNA. Theobservations werecarried out at $25^{\circ} \mathrm{C}$. Special care was taken to clean the microscope glasses (No. 0, Chance Propper, England) thoroughly before the observation to prevent DNA degradation, as well as precipitation to the glass surface. ${ }^{23}$

\section{Results and Discussion}

Cationic Surfactants-DNA Phase Behavior. The interaction between DNA and some cationic surfactants (CTAB, TTAB, and DTAB) was investigated by the study of the phase behavior. A special attention was given to the effect of the tail length of the surfactants.

A schematic representation of the ternary phase diagram is shown in Figure 2a; to better illustrate DTAB was chosen since, being the surfactant with the shorter chain length, thesamples would reach equilibrium faster, and also the surfactant forms micelles in solution up to relatively high surfactant concentrations. ${ }^{24}$ In this way wecould conduct our study until 40 wt $\%$ of DTAB. Samples at DNA concentrations higher than 4 wt \% were not prepared because of the extremely high viscosity of the solution. As expected, the aqueous mixture of DNA and cationic surfactants phase separates associatively into a diluted phaseand one phaseconcentrated in both polymer and surfactant, a precipitate. Theformation of preci pitate has been reported for several systems involving alkyltrimethylammonium bromide cationic surfactants and polyanions like poly(methacrylic acid), ${ }^{25}$ sodium hyaluronate, ${ }^{26,27}$ or sodium polyacrylate. ${ }^{28,29}$ The electrostatic

(20) Matsuzawa, Y.; Minagawa, K.; Yoshikawa, K.; Doi, M. Nudeic Acid Symp. Ser. 1991, 25, 131-132.

(21) Matsuzawa, Y.; Y oshikawa, K. Nucleosides Nucleotides 1994, 13, 1415-1423.

(22) Morén, A.; Khan, A. Langmuir 1998, 14, 6818-6826.

(23) Mel'nikov, S.; Khan, M.; Lindman, B.; J önsson, B.J . Am. Chem. Soc. 1999, 121, 1130-1136.

(24) McGrath, K. Langmuir 1995, 11, 1835-1839.

(25) Chu, D.; Thomas, J . J . Am. Chem. Soc. 1986, 108, 6270-6276.

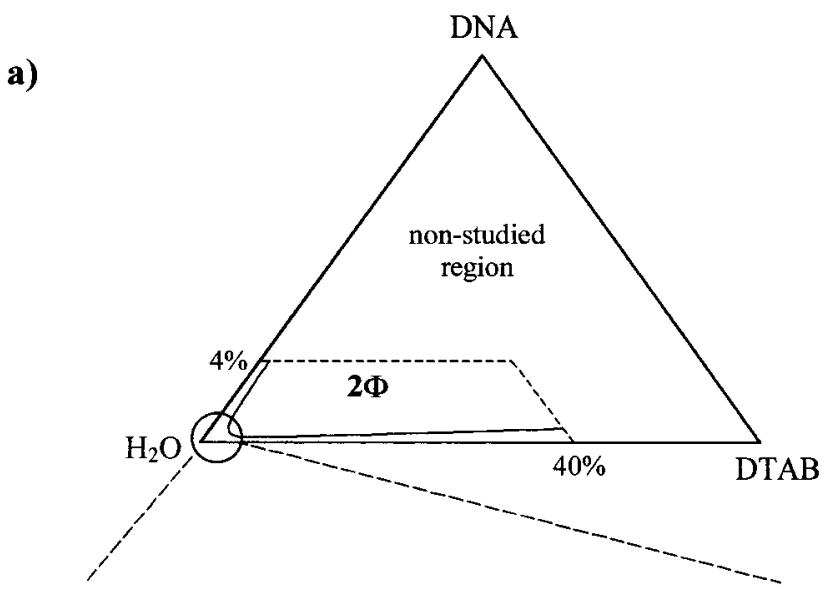

b)

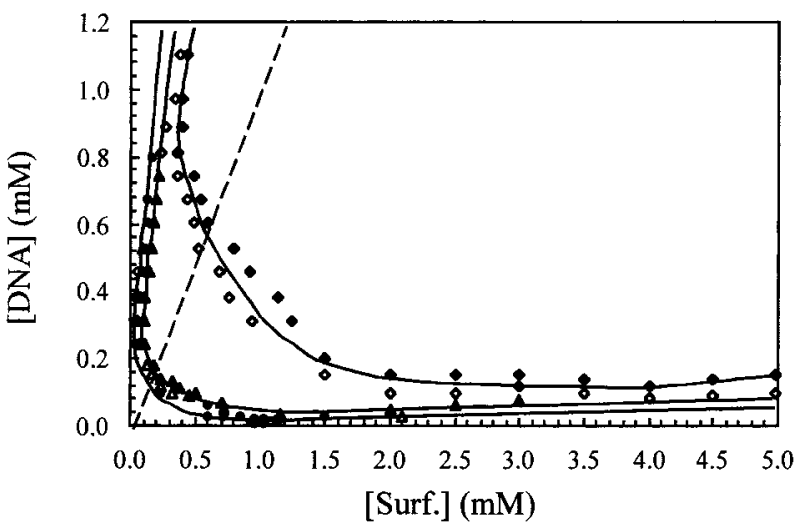

Figure 2. (a) Schematic representation of the isothermal pseudoternary phase diagram for the system DNA-DTABwater. There is a phase separation into two phases in almost the entire region considered. (b) Expanded view of the water corner of the system (diamond), including the DNA-TTABwater (triangle) and DNA-CTAB - water (circle) systems for comparison. Open symbols refer totheclear one-phasesolutions and filled symbols to two-phase samples. The dashed line indicates the charge neutralization. $\mathrm{T}=25^{\circ} \mathrm{C}$.

interactions between thecomponents areobviously strong and lead to a strong association. Surfactant aggregates induced by the polymer will act as its counterions, thereby reducing thechargeof thecomplex and theentropicdriving force for mixing and the interpolymer repulsions. ${ }^{2} \mathrm{H}$ owever, contrary to other reported pol yelectrolyte-surfactant systems, 27,28,30,31 the precipitate does not redissolve with an excess of surfactant, at least in the examined interval of concentrations. The difficulty of the redissolution of complexes composed of very highly charged polymers has been already mentioned in some studies. ${ }^{30,32,33}$

Other information drawn from the phase map is that the precipitate is formed at very low amounts of DNA and minor surfactant concentrations, far bel ow the surfactant critical micelle concentration, cmc. This is a logical observation, sincethepolyelectrolyte-oppositely charged surfactant systems are known for a critical aggregation

(26) Thalberg, K.; Lindman; B.; Karlström, G. J . Phys. Chem. 1990, 94, 4289-4295.

(27) Thal berg, K.; Lindman, B. J . Phys. Chem. 1989, 93, 1478-1483.

(28) Carnali, J . Langmuir 1993, 9, 2933-2941.

(29) Ilekti, P.; Piculell, L.; Tournilhac, F .; Cabane, B.J . Phys. Chem 1998, 102, 344-351.

(30) Goddard, E.; Hannan, R. J . Am. Oil Chem. Soc. 1977, 54, 561566.

(31) Ohbu, K.; Hiraishi, O.; Kashiwa, I.J . Am. Oil Chem. Soc. 1982, $59,108-112$

(32) Chen, L.; Yu, S.; Kagami, Y .; Gong, J .; Osada, Y. Macromolecules 1998, 31, 787-794.

(33) Kim, B.; I shizawa, M.; Gong, J .; Osada, Y. J . Polym. Sci., Part A 1999, 37, 635-644. 
concentration, cac, lower than cmc of free surfactants, often by orders of magnitude. The fact that the cationic surfactant binding occurs preferentially to anionic polyelectrolytes of high charge density ${ }^{34-36}$ further enhances this behavior.

For efficient transfection theformed complexes between the DNA and gene delivery vehicles must be stable; i.e., a phaseseparation must beavoided. Taking this and other applications into account, we found important to perform a more rigorous study of the two-phase border for the three systems. F or this, turbidity studies were conducted, and their results are presented in Figure $2 \mathrm{~b}$, as an expansion of the diluteregion of the pseudoternary phase diagram. This phasemap is presented in a si mplified twodimensional representation. Since the amount of water in these systems is extremely high, this type of repre sentation provides a better visualization. We observed that the extent of the phaseseparation increases strongly with the surfactant alkyl chain length. For example, $C T A B$, thesurfactant with thelonger chain length, binds moreeasily toDNA, leading totheformation of precipitate for smaller amounts of the polymer. This is an indication of theimportance of thehydrophobicinteractions between the surfactant molecules and an evidence of the known fact that complexes are formed with DNA and surfactant aggregates. Another substantial point is that the pre cipitate region shows a dissymmetry with respect to the surfactant and DNA axes [note the difference in scale of the axes]. This was observed for other systems 26,37 and means that an addition of smaller DNA amounts to the surfactant will causetheprecipitation of the system, while a larger amount of surfactant will be required to cause the phase separation of a more concentrated polyelectrolyte solution.

The Salt Effect. To study the effect of salt, samples were prepared according to the procedures described previously for the salt-free system. The pure water was replaced by a $0.1 \mathrm{M} \mathrm{NaBr}$ solution. The results are presented in Figure 3b. For comparison purposes, Figure 3a presents the system in the absence of salt with the same scale. It is demonstrated that there is a significant broadening of the two-phase regions for low amounts of DNA. It is known that polyelectrolytes are much more solublethan thecorresponding uncharged polymers, which is attributed to the entropy the counterion distribution. ${ }^{2}$ By adding salt, there will be a high el ectrolyte concentration in thesystem that will reduceor eliminatetheentropy contribution, leading to a phase separation.

It is a commonly accepted viewpoint that the cac of the polyelectrolyte-oppositely charged surfactant systems increases on addition of salt. ${ }^{38}$ This is due to a weakened interaction between the polymer and surfactant induced by the stabilization of micelles and a screening of the electrostatic interactions. We can observe this trend on the DNA axes two-phase boundary for the TTAB and DTAB surfactants (Figure 4, b and c). However, for the surfactant axesthepreci pitation begins for lower amounts of DNA compared to the system without salt. For the DNA-CTAB phasemap thisis al so observed, but thelines

(34) Hayakawa, K.; Santerre, J .; K wak, J . Macromol ecules 1983, 16, $1642-1645$

(35) Satake, I.; Takahashi, T.; Hayakawa, K.; Maeda, T.; Aoyagi, M . Bull. Chem. Soc. J pn. 1990, 63, 926-928.

(36) Hansson, P.; Almgren, M. J . Phys. Chem. 1996, 100, 90389046.

(37) Guillemet, F : Piculell, L.J . Phys. Chem. 1995, 99, 9201-9209.

(38) Lindman, B.; Thalberg, K. Polymer-Surfactant InteractionsRecent Devel opments. I I Interactions of Surfactants with Polymers and Proteins; Goddard, E., Ananthapadmanabhan, K., Eds.; CRC Press: Boca Raton, FL, 1993; p 203.
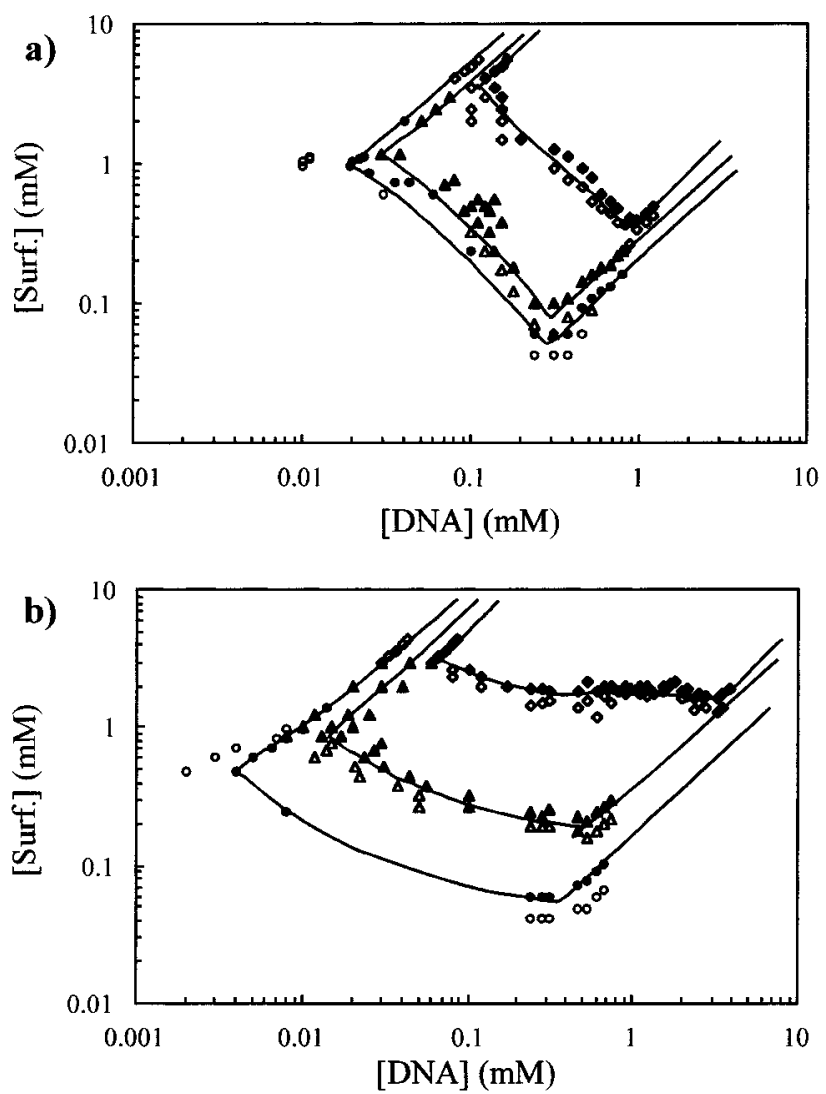

Figure 3. (a) Same as Figure $1 \mathrm{~b}$, but the phase map is represented in a logarithmic scale for better visualization of the effect of surfactant chain length on the phase transition. (b) Phase map for the three systems in the presence of $0.1 \mathrm{M}$ $\mathrm{NaBr}$. Symbols are the same as in Figure 2. $\mathrm{T}=25^{\circ} \mathrm{C}$.

of preci pitation of thesystem with and without salt overlap instead of crossing (Figure 4a). It is seen that the asymmetry of thephasediagram is further increased with the addition of salt.

This is an unexpected behavior. We believe that the knowledge of the DNA-surfactant complex structure is necessary to understand this trend. Y et, despite of all the studies made within these systems, $8,10-14$ the structure of the complex is not fully known. Further investigations are being conducted to better understand this behavior.

Analysis of the Precipitate. A study was conducted within the two-phase region to know the dependence of the amount of the precipitate on the variation of the [DTAB]/[DNA] mixing ratio, $R$, in an attempt to better understand the interaction between the surfactant and DNA molecules.

The DNA concentration was fixed at 3 wt \%, and the surfactant concentration was increased stepwise until a maximum of $R=7$. The samples were analyzed with respect to the precipitate and water in the supernatant.

The results are plotted in Figure 5. By observing the dependence of the amount of precipitate on the DNA/ surfactant mixing ratio, it can be clearly seen that the precipitate starts to form at very low concentrations of surfactant, as shown previously. The plot of the water content in the supernatant gives us more information. Also, the amount of water increases with the increase of the surfactant concentration, due to the formation of the preci pitate, which decreases the concentration of DNA in solution. At a mixing ratio of approximately 1.0 the percentage of water in the supernatant reaches a maximum of almost 100. After that it decreases again, with theincrease of surfactant in solution. Wecan deducefrom 

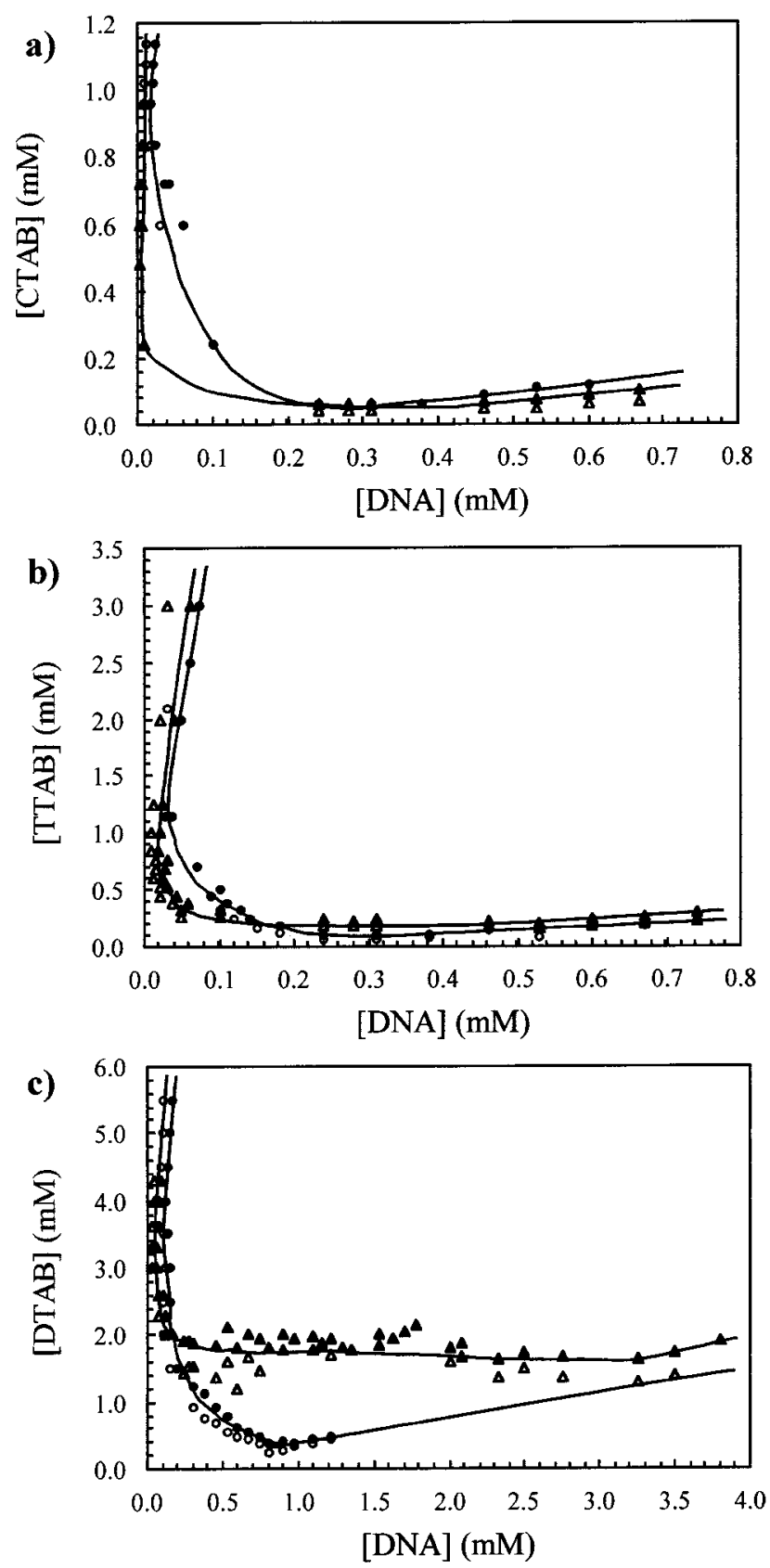

Figure 4. Effect of theaddition of $\mathrm{NaBr}$ on the phase behavior of the aqueous systems DNA-CTAB (a), DNA-TTAB (b), and DNA-DTAB (c). Circles represent samples without salt and triangles samples in the presence of salt. As before, open circles refer to clear one-phase solution and filled symbols to twophase samples. $\mathrm{T}=25^{\circ} \mathrm{C}$.

this that the maximum amount of precipitate takes place at a point closetothechargeneutralization, corresponding to one surfactant molecule to each DNA negative charge. In Figure $5 \mathrm{~b}$ a broken line that represents the original amount of water in the samples is constructed. It is easily observed that the decrease of the amount of water in the supernatant is parallel to this line. This gives us the indication that the surfactant added to the samples remains in the supernatant, probably as free micelles, and that the amount of precipitate is constant in this region. On the precipitate curve (Figure $5 a$ ) this fact is not visible in the experimental points. This apparent increase in the amount of the precipitate is due, possibly, tothesupernatant that invariably stays within thesample contributing erroneously totheweight. F or low surfactant

a)

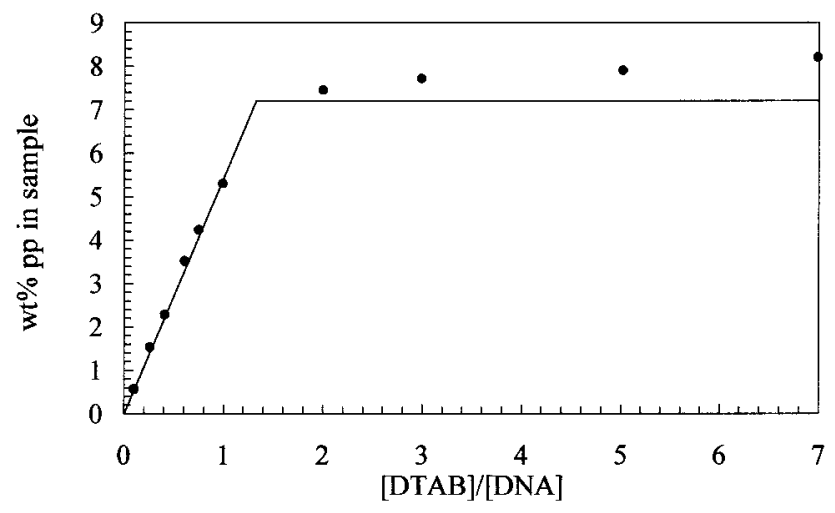

b)

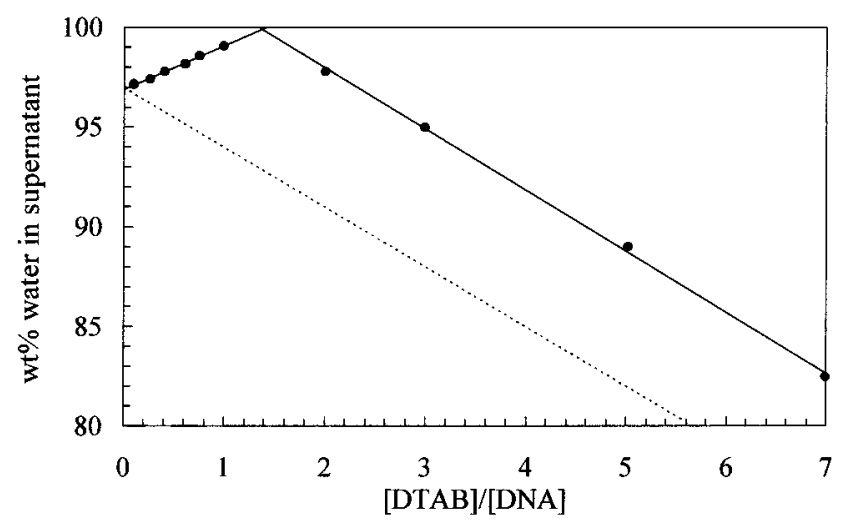

Figure 5. (a) Weight percent precipitate in thesampleversus themixing ratio between surfactant and DNA, [DTAB]/[DNA], at a constant 3 wt \% DNA. (b) Dependence of the amount of water in the supernatant on the molar ratio [DTAB ]/[DNA] at 3 wt \% DNA. The dashed line represents the decrease of the amount of water due to the increase of the concentration of surfactant.

concentrations this is negligible, but for highly concentrated DTAB samples this contribution cannot be ignored.

The observation that the precipitate reaches the maximum amount near the chargeneutralization and remains constant, at least within the studied region, is in good agreement with the nonredissolution of DNA - surfactant complexes. Since there is no binding of the surfactant to the complex after its neutralization, an inversion of the complex charge is not observed, as happens with many similar systems. ${ }^{27-30}$

Analysis of the Precipitate in the Presence of Salt. Samples with thesamecomposition as thosecorresponding to the salt-free system were prepared with $0.10 \mathrm{M} \mathrm{NaBr}$. The results are compared in Figure 6 . We can observe that the two systems' behavior is quite similar. There is a sharp increasein theamount of precipitatein thesample with the addition of surfactant, and the maximum of precipitation occurs for a mixing ratio of approximately 1 , corresponding to charge neutralization. By observing the percentage of water in the supernatant, we can see that the precipitate starts to form at higher mixing ratios and that the amount of water remains almost constant until $R=0.25$. It can also be observed that the samples with salt contain about $0.5 \mathrm{wt} \%$ less water than those of the salt-free system. This value corresponds to the salt contribution to the weight of the sample and means, probably, that the major fraction of the salt is dissolved in the supernatant. 
a)

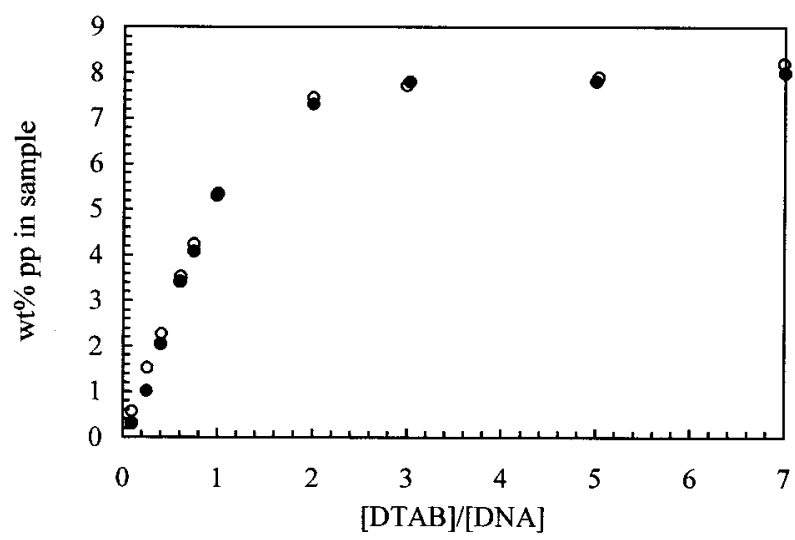

b)

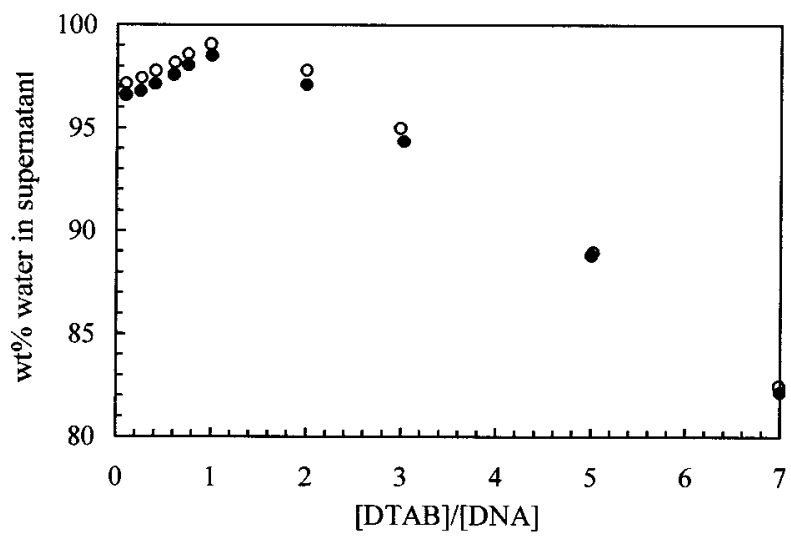

Figure 6. (a) Effect of theaddition of salt on the weight percent precipitate for samples versus the molar ratio between surfactant and DNA at a constant DNA concentration. (b) Effect of the addition of salt on the dependence of the amount of water in the supernatant on the molar ratio [DTAB]/[DNA] at $3 \mathrm{wt}$ $\%$ DNA. Open circles correspond to the system containing pure water and the filled ones to the samples prepared with $0.1 \mathrm{M}$ $\mathrm{NaBr}$.

DNA Phase Behavior in Very Diluted Samples. In a previous section we observed the effect of surfactant chain length on the DNA interaction with cationic surfactants, at relatively high DNA concentrations, i.e., in a "macroscopic" study. To better understand this interaction, it is pertinent to study the same system by using a microscopic scale. Fluorescence microscopy is a technique that has been recently used in thestudy of DNA conformational behavior in the presence of various cosolutes, and its main advantage is to allow for the visualization of single molecules in solution. DNA molecules in aqueous solution present an extended conformation, flowing in the solution and exhibiting a relatively slow wormlike motion; i.e., they are in the unfolded coil conformation. When, for example, TTAB was added to the DNA solution above a certain concentration, $2.0 \times$ $10^{-5} \mathrm{M}$, weobserved a coexistence region of some compact molecules in solution al ong with DNA coils. Thesecompact molecules that present a high fluorescence intensity, and a long-axis length less than $1.0 \mu \mathrm{m}$, are denoted as DNA globules. With further increase of the surfactant concentration, $[T T A B]=8.0 \times 10^{-5} \mathrm{M}$, we reached a region where only DNA gl obules were detected. Theseresultsal ong with those for DNA phase behavior in the presence of CTAB and DTAB are presented in Table 1.

By looking at the conformational behavior of DNA molecules, we first conclude that a larger amount of the
Table 1. Characterization of the Interaction between DNA and Cationic Surfactants ${ }^{a}$

\begin{tabular}{lccc}
\hline & $\mathrm{C}_{0}(\mu \mathrm{M})$ & $\mathrm{C}_{1}(\mu \mathrm{M})$ & $\Delta \mathrm{C}(\mu \mathrm{M})$ \\
\hline CTAB & 8.0 & 24.0 & 16.0 \\
TTAB & 20.0 & 80.0 & 60.0 \\
DTAB & 80.0 & 300.0 & 220.0
\end{tabular}

a $C_{0}$ represents the concentration at which globules were first detected in the solution, and $\mathrm{C}_{1}$ is the disappearance of a last DNA globule. $\Delta \mathrm{C}$ is the coexistence interval width. $\mathrm{T}=25^{\circ} \mathrm{C}$.

shorter chain length surfactant is needed to induce the compaction of DNA macromolecules. We observed that the coexistence region begins for concentrations 8.0 and $80.0 \mu \mathrm{M}$ of CTAB and DTAB, respectively. These results arein good agreement with theresults of previous sections, since we observed that a higher concentration of DTAB is needed for theformation of preci pitate. Wecan associate the precipitation with theformation of globules by taking into account the difference in the DNA concentration in both systems. A valuableparameter of DNA-amphiphile interaction is the width of the coexistence region. We can see that the coexistence interval is narrower for DNACTAB systems and becomes wi der for theshorter-chained surfactants. I t was emphasized before that the binding of the surfactant molecules to DNA is highly cooperative being as described by binding isotherms. ${ }^{6}$ In the sigmoidally shaped plots, theamount of surfactant bound to the polymers, binding degree, $\beta$, is plotted against the free surfactant concentration. By using binding isotherms, ${ }^{6}$ $K$ wak et al. have shown the effects of surfactant chain length in theDNA-surfactant interactions. For thelonger surfactant chains the binding isotherm has an abrupt behavior, whilefor a short surfactant alkyl chain the plot has a less steep profile. It is not surprising that the slope of the cooperative part of the binding isotherm was attributed to the coexistence region. ${ }^{39}$ Our results with TTAB and DTAB are in a good agreement with these observations. I t should be, neverthel ess, taken intoaccount our disagreement with theuse of theterm "binding degree" and what it represents in these systems. ${ }^{40,41}$ The DNA molecules undergo a discrete or a first-order phase transition in the presence of cationic surfactants.

Associative phase behavior is well-documented for mixed aqueous systems of a polyelectrolyte and an oppositely charged surfactant ${ }^{16,25-27,30,32-36,38,39}$ and so is also the effect of surfactant on the polyion conformation. $26-28,32,33,39$ However, the findings for the flexible polyions of lower charge density differ qualitatively from what we find here for DNA. Thus, in previously studied cases, like hyaluronan and polyacrylate, high concentrations of surfactant have to be added before phase separation occurs. Furthermore, thechangein polyion extension is gradual, with no indication of two dominating states. With theflexiblelow charge density cases it can beinferred that while surfactant binding is cooperative, in that it results in surfactant self-assembly aggregates and is characterized by a well-defined critical association concentration, there is an essential ly uniform distribution of surfactant aggregates among the different polyions. Phase separation takes place when the net charge of polyionsurfactant aggregates attains a low value, and the distribution explains why rather high amounts of surfactant are needed for phaseseparation in these cases. F or

(39) Mel'nikov, S.; Segeyev, V.; Yoshikawa, K. J . Am. Chem. Soc. 1995, 117, 9951-9956.

(40) Mel'nikov, S.; Sergeyev, V.; Mel'nikova, Y.; Yoshikawa, K. J . Chem. Soc., Faraday Trans. 1997, 93, 283-288.

(41) Mel'nikov, S.; Sergeyev, V.; Yoshikawa, K.; Takahashi, H.; Hatta I. J . Chem. Phys. 1997, 107, 6917-6923. 
DNA, the very low values of surfactant concentration at which phase separation starts demonstrate a different binding situation and an all or none binding: as binding to DNA starts, further binding is facilitated and one DNA double-helix molecule is saturated before binding starts at another; i.e., there is a double cooperativity. This is directly confirmed by thefluorescence mi croscopy results, demonstrating the coexistence of original extended coils and globules compacted to the final state.

It is important to emphasize the role of attractive interactions in compaction and phase behavior. Compaction and phase behavior are driven by attractive interactions between different parts of a DNA double helix and between double helices, respectively. As argued bel ow we ascribe these attractive interactions to attractive electrostaticinteractions duetothe correlation effects arising in the presence of multivalent counterions. ${ }^{42}$

With surfactant binding occurring in theform of discrete micelles, this can be understood if the local perturbation of the conformation of the DNA chain facilitates micelle association in adjacent parts. However, there are strong indications that the surfactant binding to DNA leads to the formation of highly extended aggregates; X-ray diffraction patterns have been interpreted to suggest the presence of reversed hexagonal phase. ${ }^{10}$ With preferred very large, "unl imited", aggregates the highly cooperative DNA folding can beeasily understood. However, weknow that the cooperative folding of DNA is not limited to selfaggregating cationicsurfactants; it al so occurs for cationic polymers and multivalent counterions. It appears, therefore, that we best consider the cationic surfactant selfassemblies as attractive correlation interactions between different parts of a DNA molecule, thus inducing a compaction; therole of ion-ion correlation effects in DNA compaction has been discussed el sewhere. ${ }^{23}$ The complex effect of added salt can bereferred to an interplay between the effect of monovalent ions on surfactant self-assembly, on DNA chains and chain-chain association, the latter also promoted by the attractive interactions. However, DNA-DNA association is probably kinetically unfavorable under most experimental conditions for high molecular weight DNA.

(42) Gullbrand, L.; önsson, B.; Wennerström, H.; Linse, P. J . Chem. Phys. 1984, 80, 2221-2228.

\section{Conclusions}

A study of the phase behavior of the DNA-CTAB/TTAB/ DTAB aqueous system was carried out. These systems show a strong associative behavior having a largetendency to phase separate even for low surfactant and DNA concentrations. As predicted, a smaller amount of the longer chain length surfactant is needed to promote the phase separation. An asymmetry of thetwo-phase region with respect to the stoichiometric line was observed. The redissolution of the precipitatewas not achieved by adding an excess of surfactant, probably due to the formation of a stoichiometric complex.

Unexpectedly, an enlargement of the asymmetry was obtained with theaddition of $\mathrm{NaBr}$. This fact was explained by screening of the electrostatic interactions between the DNA and surfactant aggregates, which leads to an increase of the cac and delays the formation of precipitatefrom one side. On theother hand, we could not explain thefacilitated formation of precipitate for lower amounts of DNA and higher surfactant concentrations.

For the samesystems the conformational behavior was studied for very diluted solutions by fluorescence microscopy. Theresults from both studies are in good agreement, since a larger concentration of DTAB is needed to observe the compaction of DNA molecules. Also, we observed that the coexistenceinterval is narrower for CTAB and becomes wider for the surfactants of shorter chains.

Despite showing a similar associative phase behavior as other polyelectrolytes in the presence of oppositely charged surfactants, DNA demonstrates a different binding situation. The double cooperativity had been al ready observed by fluorescencemicroscopy and explains thevery Iow values of surfactant concentration at which phase separation starts. This behavior gives strong indications that thesurfactant bindingtoDNA leads totheformation of highly extended aggregates.

Acknowledgment. This work was supported by grants from J NICT and Praxis XXI (project 2/2.1/QUI/ 411/94), EU Erasmus Program, the Caloust Gulbenkian Foundation, the Swedish Research Council for Engineering Sciences (TFR), and the Center for Amphiphilic Polymers (CAP), in Lund. Wethank Håkan Wennerström and Lennart Piculell for fruitful suggestions.

LA000640F 